\title{
The formation algorithm of social-projected competences of experts in ecology
}

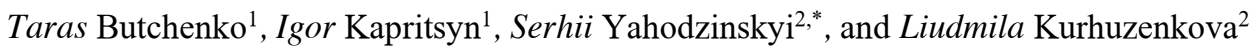 \\ ${ }^{1}$ Zaporizhia National University, 69063, Zhukovskogo st., Ukraine \\ ${ }^{2}$ International European University, 02000, Vernadskogo av., Ukraine
}

\begin{abstract}
The article is devoted to the analysis of the algorithm of formation of social and project competencies of ecologists as a basis for the development of appropriate training programs. For this purpose, the analysis of process of social and ecological designing in which valuewilled, conceptual and normative-administrative stages are allocated is carried out. Accordingly, the content of social and project competencies of experts in ecology is determined, and the programming of the formation of social and project competence of experts in ecology is reoriented to the development of the ability of experts in ecology: 1) identify and articulate the deep integrated socio-ecological interests of a particular community; 2) to substantiate the social-project idea as an explanation of the laws of translational social transformations of the natural environment; 3) to overcome the dogmatism of outdated linguistic non-normative forms, and instead to be able to discover new social and project eco-meanings in them.
\end{abstract}

\section{Introduction}

Precondition for the implementation of international environmental standards, the realization of programs for sustainable development of society is the formation of social and project competence of experts in ecology and students of appropriate specialties and educational programs. At the same time, the educational literature mainly covers the general components of the project competence of ecology experts in the field of purely environmental design. [1-4]. The issue of forming social and project competencies needed to change social relations in behalf of ecology is ignored. In practice, the study of this important dimension of socio-ecological project activities is limited to acquaintance of the audience with the technique of writing socio-project applications for certain grant competitions on environmental issues. Perhaps, this is clearly not enough.

Therefore, the purpose of this article is to reveal the algorithm of formation of social and project competencies of experts in ecology. Thus, a basis is created for the development of appropriate training programs and improvement of the educational and methodological base of professional education of environmentalists.

In our opinion, the algorithm for the formation of socio-project competencies should be correlated with the real socio-ecological project process, in which we can distinguish the following stages: 1) value-willed, the purpose of which is to generate motivation and

* Corresponding author: yahodzinskyi.serhii@gmail.com 
imagination required for project design of ecological and social transformations; 2) conceptual, which develops project ideas and concepts; 3) normative-administrative, the purpose of which is to ensure normative term and organization of implementation of the project plan [5].

\section{Materials and Methods}

These stages are interrelated. Thus, the purpose of the value-willed stage is to generate motivation for creative search, without which it is impossible to develop new ideas and concepts of socio-ecological projects. In turn, the theoretical depth of environmental concepts determines the depth of awareness of the ecological needs of the project audience, and hence the scale of socio-ecological project interests and goals. At the same time, the best goals, ideas, concepts are unattainable without a proper language and normative form and socio-administrative efforts, thanks to which socio-ecological projects are realized and implemented by participants in social transformations of the natural environment. Accordingly, we are going to try to determine the main components of the algorithm for the formation of socio-project competencies of experts in ecology based on the analysis of the main stages of the socio-ecological project process.

Where does the spiritual energy come from, which forces to construct new social models of the organization of the natural environment, not to stop at what has been achieved, to always strive to continue the creation of new, more perfect forms of life? In our view, it is born in the process of awareness of socio-ecological needs, which reflect the lack of certain social relations or the inadequacy of existing ones (in particular, inadequate organization of man-made environment, limited access of certain categories of the population to significant environmental resources, etc. However, this does not mean that material-technical issues do not concern the developers of social eco-projects. They are in the field of view of social designers, but indirectly, modified in the awareness of the inadequacy of certain technical means of maintaining and developing a dynamic material and energy balance between man and nature.

\section{Value-willed stage}

Socio-ecological needs are actualized during the crisis destabilization of natural and social life of certain people, groups, when they lose confidence that the natural, spontaneous course of things is able to ensure their survival and development. However, the ecological crisis in social life and public consciousness does not always have purely negative effects. Probably, it is not accidental that in Chinese the word 'crisis' consists of two hieroglyphs 危 (wei) and 机 (ji), where the first indicates danger, and the second - an important moment, an opportunity [6].

Crisis ecological situation contributes to the formation of socio-project interests as a special project awareness of a particular socio-ecological need and possible ways to meet it. The birth and development of environmental social and project interests can be represented as a polyphase process.

The first phase is related to the psychological level of consciousness and has a manifaction in the form of emotional and sensory awareness localized within a certain time and space of a specific biosocial deficiency (desire, feelings, affinity, etc.) and semiconscious development against this background of human premonitions and intuition, imagination and memory. dreams and fantasies.

In the second phase, the tension between the real and the desired is 'removed' through the formation of an ideal image of the desired possible way out of the situation of scarcity - 
the purpose of constructive and spiritual pursuits, and the formation of forms of willed, conscious regulation of the spiritual efforts of the subject orientations.

On the third - internal purposeful willed activity of eco-interest rises to the conceptualtheoretical level, where it gradually turns first into an idea, then - into a concept and, finally - into a theory, and the situation of scarcity begins to be realized as an ecological designtheoretical problem - heuristic task.

Finally, socio-project ecological interest shifts to the phase of technologicalization, where theoretical ideas and principles are formalized in documented environmental projects of social and natural transformations, official decisions and regulations, assimilated by other members of society and, finally, practically implemented. Socio-project ecological interest determines the formation of search motivation, which, in turn, 'launches' the imagination as the ability of man to mentally reproduce what does not exist in reality.

If the creation or arrangement of a certain object, which is associated with the satisfaction of socio-ecological needs, is perceived as a relatively accessible, fundamentally possible goal, then there are favourable conditions for 'switching' willed mechanisms of conscious embodiment of the future and development of the project imagination. The project eco-imagination can then become the object of management, for example, through the use of:

- at the level of personality - visualization techniques, in other words, the deliberate invention of certain eco-images;

- at the group level - special procedures for collective discussion of an ecological problem (in particular, the method of 'brainstorming');

- at the level of society - management of public opinion (eco-advertising, propaganda, competitions, etc.).

It is impossible to control the ecological imagination of a social subject without realizing the significance of its possible means and consequences. In other words, it needs ecological values - a specific form of ideal reflection of the meaning of the objective world, which is carried out in accordance with the needs, interests, goals of man. The connection of values with needs, interests and goals is specified in the meaning of the term 'assessment', which means a certain way of establishing the significance of an environmental object for the subject who acts and learns.

The characters of evaluation depend on the ecological ideal - the central element of the system of eco-values, which fixes the model of social perfection of the environment as a reference point for human activity. In essence, the ideal is a reflection of the highest positive value of the objective trends in the development of human existence, the maintenance of which makes it possible to remove the general and ecological imperfections of social reality. In this capacity, the ideal forms the highest norm, a model that has a powerful regulatory effect on the nature of the choice of specific forms of satisfaction of a need and the development of the relevant interest.

For a long time, the establishment of a social eco-ideal was associated with the idealization of certain aspects of socio-historical experience. In particular, one of the oldest and most common ideals is the idea of the past 'golden age' as a time of the highest social harmony in the relationship between nature, man and society. The retrospective method of forming the eco-ideal had its advantages, aimed at reproducing the tested patterns of life, amortizing the recklessness of innovative initiatives. However, in the extreme, such a conservative guideline defined alienation from the ever-changing reality.

With the assertion of the values of the active human attitude to the world and oneself, the search for a social eco-ideal is reoriented to the future, to the discovery of new forms of social perfection of the natural environment. Adjusting to a critical understanding of the relationship between nature and society, social eco-ideals accustomed man to a purposeful search for ways to manage their own future. But there was a threat of alienation of ideals 
from reality, and thus - instead of projects created social eco-utopias. Therefore, in order not to remain at the level of utopian thinking, there should be a transition to the next stage of the project process.

\section{Conceptual stage}

The basis of the conceptual stage of socio-ecological design is the idea as a form of awareness of the purpose and methods of cognition and project transformation of a certain set of social relations. The formation and development of an idea is lconnected with the formation and development of holistic socio-ecological knowledge, for which it acts a systemic role. In turn, in order to this mission, an idea necessarily needs a concept - a set of concepts by which it is explained, justified, understood and interpreted. Organizing thinking and being realized in all kinds of human activity, the concept and idea go from the daily to the theoretical level, from mythology and religion to philosophy and science. At any level of social consciousness, in any of its forms, the conceptual development of the idea was a way to create 'project' blocks of understanding the ways of mastering the natural and social worlds.

The basis for the formation of conceptual ideas of socio-ecological projects - the daily practice of human participation in society. Ideas and concepts of transformation arose in the process of synthesis of everyday views, ideas and opinions on pressing issues of public environmental management. Guided by common sense, armed with the method of 'through trial and error', people reflected on spiritual and practical experience, more or less systematized empirical observations, identifying and excluding erroneous models of certain possible actions to transform the natural environment of society.

Despite the fact that in the modern era the cost of erroneous solution to socio-ecological problems is incredibly high, the level of application of more accurate scientific and theoretical methods and forms of design remains low. This is primarily due to the fact that mastering scientific theory requires work and time, but not everyone has the appropriate level of consciousness and self-discipline. The justification for this passivity is the belief that common sense responds the requirements of practice more than theory.

Exaggerating the role of common sense limits the potential of socio-ecological design, as it hinders the prospects of development, immerses a person in everyday life, reducing his ability to adapt to new environmental challenges (example - the situation with COVID-19 or global warming). Meanwhile, one should not absolutize theoretical concepts, underestimating everyday ideas. Modern scientific theories of ecological friendly environment are not the final reflection of reality, practice always reveals its draw bags. If theoretical thought does not improve in response to the new challenges of history, it does not keep up with life and becomes a dogma. In this case, it may turn out that everyday ecorepresentations are much closer to practical realities than scientific-theoretical ones. After all, the knowledge of the relationship between man and society takes place at the level of everyday consciousness, because reflecting the world of natural and social phenomena, and albeit fragmentary, it still reflects certain essential eco-connections.

One of the features of daily ideas is their connection with the mythological forms of social consciousness, which, being established in the distant past, are constantly restored to our time. Mythological eco-representations recover an ambiguous role in the process of cognitive-project activity. They stimulate the imagination of the designer, given the opportunity to synthesize certain information, to move from chaotic ideas about something to orderly knowledge, which often receives unparalleled scientific significance. Myths 'close' the incompleteness and relativity of scientific and rational ideas, act as a starting point for many innovative projects. In particular, mythological images of the harmonious integrity of nature and archaic communities, nowadays are the basis for the development of 
many scientific projects to restore the use of traditional natural resources in construction, energy conservation, nutrition, but, of course, on a qualitatively different technological and social basis.

In addition, mythological images-concepts are used in social design to convey to the mass audience the scientific and theoretical idea of a social eco-project. To do this, the idea must be somewhat simplified, formulated in the form of concise proclamations, slogans, advertising slogans focused on the use of already known stereotypes and mythical images, which are easily perceived by the mass consciousness. However, this process can lead to the replacement of the scientific and conceptual content of the social eco-project by mythologies, the dogmatic content of which can distort the intentions of the designers. The main task of social design is to provide such scientific and theoretical depth of forms of its popularization, adhering to scientific and theoretical principles of social and ecological design - fundamental theoretical principles, which reflect the natural connections of the set of relations between man, society and nature.

The starting point is the principle of objectivity, according to which the socio-project idea will be feasible only to the extent that it corresponds to the natural possibilities of the changing natural and social system.

Important is the principle of systematization, which orients the ecologist to reproduce the transformed area of natural and social reality as a whole set of individual elements, the strength of internal ties between which exceeds the strength of external links with elements of other systems.

The condition for achieving such a result is the delimitation in the transformed systemic integrity of man, society and nature, the necessary connections from accidental, essential from insignificant, ie the disclosure of the laws of its functioning in the current social situation.

In turn, the creation of the dynamics of action is the principle of the principle of historicism, the implementation of which requires the return of historical patterns of development of forms of organization of the natural and social environment of a society. For a social eco-project, it is important to determine an acceptable measure of the combination of universal, international and national-cultural experience of the relevant transformations, using, in particular, the achievements of comparative studies in the field of ecology, nature management, etc.

The creative nature of social design causes significant difficulties, especially in the initial phase of finding an idea. Therefore, the ability to use techniques to free consciousness from environmental stereotypes, awakening creative intuition and imagination play an important role. At the Reanji Temple in Japan, a change in the position of the observer in the 'Garden of Fifteen Stones' opens up new objects previously invisible. By analogy, to activate the conceptual level of socio-ecological design are useful methods aimed at changing the social position of the ecologist-designer, providing him with certain conditions for expanding worldview, thus opening new prospects for significant natural and social self-realization. It is recommended to use various methods for this purpose.

Thus, the methodology of social science comparative studies can be useful, within which systemic, historical, structural-functional analysis and others are united by the focus on comparison, comparison of certain social systems. On the basis of comparative studies, in particular, benchmarking technology was created, which regulates the assimilation of advanced environmental experience of man and his communities in order to overcome weaknesses, identify and implement opportunities for further development. In essence, it is a certain way of motivation for self-improvement and, at the same time, taking into account mistakes in the preparation and implementation of social eco-projects.

The program of social-project eco-benchmarking can include various research tools: internships, expert meetings, conferences, involvement in the comparative analysis of 
stakeholders, for example, the German technology 'circle-comparison', generalization of the data through comparative analysis of the environment certain communities.

With the help of comparative research, it is possible to determine the general and special characteristics of natural and social transformations in different social communities (in particular, communities, labor collectives, etc.), to approach the discovery of scientific laws and patterns, knowledge of which creates a scientific and theoretical basis for formulating effective social design eco-norms and regulations.

Finally, the final part of the preparation of the concept of the eco-project involves the ability to reflect on the conceptual design to determine its relevance to the social needs and interests of the target audience, identify weaknesses and opportunities to reduce them. At this stage, it may be necessary to return to the conceptual development of a certain idea or to develop a new one. In essence, in this way there is a kind of thought experiment, the purpose of which is to pre-assess the degree of practical feasibility of a social eco-project.

\section{Formation of regulatory and managerial competence}

The leading functional purpose of the normative-administrative stage of the process of social-ecological design is the linguistic-normative design of project thinking and its results (ideas, concepts, projects) for the organization of actions and behavior of participants in ecological transformations.

The use of artificial sign systems with strictly limited semantic content and clearly defined rules for the construction of sign structures (special scientific and technical terms, designations, drawings, etc.) dominates in engineering and technical design. The possibility of such a level of formalization is determined by the universality of natural relations of natural phenomena, which allows extrapolation of the rules of mathematics, cybernetics, physics, chemistry, etc. to very broad classes of natural objects, the transformation of which is projected. Accordingly, a basis is formed for a clear algorithmization of the designer's work and further activities for the practical creation of the designed object.

In comparison, the situation is much more complicated in the social and project sphere, where the use of symbolic resources of natural languages prevails. Given their ambiguity and logical contradiction (as rightly pointed out by the authors [5]), using language tools, it is very difficult to clearly regulate the process of thinking about socio-environmental innovations on engineering models. Participants in socio-ecological design face, first of all, the problem of objectively existing alternative interpretations and interpretations, which in extreme cases results in a real threat of losing the conceptual idea of transforming into infinity the possible meanings of language signs. Even the development of specialized social and project ecological terminology by means of science, official documentation and legislative techniques does not solve the problem in general.

In social-project ecological practice there is an active use of non-verbal signs borrowed from the field of engineering design. Most often, as noted above, they are found in the dimension of economic and project activities, which unfolds in a special monetary plane directly reflecting the material and natural, technical and engineering patterns of ecological friendly environment. In addition, purely technical projects often formalize certain socioconstructive ideas, ensuring the organization of both logistical and natural-social space. Recently in social design there is a tendency to intensify the use of syntactic sign systems based on the rules of construction of sign structures regardless of their semantic content (including mathematical and logical), resulting from attempts to attract the latest approaches and methods of cybernetics, mathematics and logic.

But this trend is weak, which can be attributed to the subjective unwillingness of the general public to accept the rather complex mathematical and logical terminology. At the same time, the main reason for its inhibition is the impossibility to finally fit the 
contradictory, nonlinear nature of human natural and social life into the formalized logic of artificial sign systems. Adequately reproducing the quantitative aspects of human social and natural existence, they demonstrate the inability to take into account its specific qualitative relations, in the content of which there is a generally unmeasurable sphere of human subjectivity, carried out in emotional, sensory, value relation to the natural world. Therefore, a strictly formalized political constitution, drafted, for example, in the spirit of 'arithmetic laws' of utilitarian's, facing the real natural environment of man and in sharp conflict with its nonlinear diversity, shows its utopianism and can play the role of imposing authoritarian will of designers and designers. and values of other social actors [8].

The low ability of the natural language sign system to regulate project thinking can be its advantage, which, provided a certain degree of freedom of possible interpretations provides spatio-temporal plasticity of language forms, their openness to ideological initiatives by all participants in social interaction of different generations. realization of the dialogic essence of social design. In addition, understanding the ways of certain ecotransformations in social life and hoping for their implementation in reality, the designer is objectively forced to refer to natural languages as common and most common in public communications sign systems, because their use gives him a chance to be heard. and receive massive support, without which even the best eco-project will remain unrealized.

\section{Discussion}

It is not enough to be a reasonable and convincing image of the future for a feasible socioproject plan of ecological transformations. In addition, it should be able to serve as a basis for the development of new comprehensive regulations, sustainable rules of social behavior and activities, the introduction and compliance of which only allows the successful implementation of the project as a process of artificial transformation of a particular environment [9]. In this regard, social ecological norms, fixing a new socially acceptable measure of human behavior and activities, play the role of supporting structures of the designed management model of a particular natural and social system.

Embodying the project eco-concept, ensuring its perception in general, the organizational rules established during the design, claiming the status of the norm, can be considered as a kind of criterion for the conceptual depth of the socio-environmental project. The fact is that to acquire normative properties, that is, to become a true standard, a model of mass acts of social behavior, can only be a rule that reflects in advance the patterns of the dimension of relations between nature and society, the transformation of which is projected. Ideological-conceptual and value-willed components of design thinking, filling the content of the generated concrete-practical prescriptions, and show here the degree of their conformity to practical realities.

At the same time, it is important to have a high level of mastery of regulatory techniques as a set of linguistic and logical techniques, methods, special tools and procedures for developing design standards in the form of provisions of the socioecological project [10]. Without appropriate knowledge and skills, it is impossible to ensure the implementation of even ideologically deep social eco-projects.

Technically, the functioning of the social norm in a 'dialogical' mode, open to possible innovations and clarifications by all participants in social cooperation, is provided by different degrees of flexibility of its structural elements: disposition, which determines the characteristics of the situation of its application; imperative, which is the formulation of a requirement for the proper conduct of subjects subject to its action.

Changing depends on belonging to a certain kind of social norms and the specific historical situation of rule-making, the degree of flexibility of disposition and imperative 
has, at the same time, certain absolute qualitative limits beyond which the norm may lose its dialogic substantiality and eventually lose its normativeness.

Thus, over-concretization of the disposition and categorization of the imperative is the basis for the emergence of such a phenomenon as 'stillborn' ecological norm, which, of course, may in some cases even be implemented as an individual prescription, order, especially if they are provided by violence or manipulation, but will never become a universal and established rule of conduct, massively reproduced over a long period.

In turn, the exaggeration of the degree of abstractness of the disposition and softness of the imperative also has a detrimental effect: there is a phantom norm - a vague, declarative formation, which is unable to fulfill a direct mission to regulate public relations in the field of nature and human environment. can only in certain circumstances act as one of the ideologues - a component of manipulative technocratic space.

\section{Conclusions}

The program of formation of social and project competence of ecologists was built on the described algorithm, intends to join the decisions in at least three years.

The first is to provide a set of knowledge, skills and abilities of facilitation, necessary for the realization of social and ecological needs and the formation of the corresponding search and design interest. It should be emphasized that in socio-ecological project activities facilitative practices have a pronounced dialogical nature and involve a high level of mastery of techniques of creative dialogue, organization and conduct of group discussions, arguments, including focus group, business game, psychodrama and others. An indicator of the level of mastery of all these methods is the ability to express a deep integrated socio-ecological interest of the local community.

The second is the activation of the conceptual potential of ecologists, the formation of knowledge, skills and abilities of analytical thinking, reflection, including in the mode of philosophical generalizations and scientific research. The indicator of level of possession of the specified competences - ability to define socially-project and some form of reflection of a certain law of translational social transformations of natural environment.

The third is the development of knowledge, skills and abilities of sign-normative design and management of social eco-projects. First of all, it is a question of high level of knowledge of socially-project-written language, methods of formulation of design rulesprescriptions and modern techniques of presentation of project ideas, including in a mode of preparation of regulatory legal initiatives. One of the key criteria of competence here is the content of the profit of the dogmatism of obsolete linguistic alien forms, the anatomy of the content, which opens up in new socio-project ecological purports and meanings.

\section{References}

1. Sim Van der. Ryn, Ecological design. Cowan 10th anniversary ed. Island Press, Washington-London (2007)

2. N. J. Todd, A safe and sustainable world: the promise of ecological design. IslandPress, Washington (2005)

3. Yu. Volkov, Ekologicheskoe proektirovanie, otsenka vozdeystviya na okruzhayuschuyu sredu i sertifikatsiya, Tomsk (2011)

4. K. Dyakonov, L. Doncheva, Ekologicheskoe proektirovanie i ekspertiza. Moscow (2005) 
5. T. Butchenko, Sotsialno-politychne proektuvannia: problema vzaiemozviazku suspilnykh potreb i derzhavnykh interesiv. Zaporizhzhia: KSK-Alians (2011)

6. J. K. Remark, sat the Convocation on of the United Negro College Fund, Indianapolis, Indiana, April 12 (1959) https://www.jfklibrary.org/archives/other-resources/john-fkennedy-speeches/indianapolis-in-19590412 (Last accessed 22.01.2021)

7. Etyudyi po sotsialnoy inzhenerii: ot utopii $\mathrm{k}$ organizatsii (Moscow, Editorial URSS, 2002)

8. J. C. Scott, Seeing like a state: how certain schemes to improve the human condition have failed. Yale University Press New Haven and London (1998)

9. S. Yahodzinskyi, Anthropomorphic Networks as Representatives of Global Consciousness. Philosophy and Cosmology, 20 (2018)

10. L. Orochovska, U. Koshetar, Ideas of the cosmism philosophy natural-scientific direction within media space and social-economic space. E3S Web of Conferences, 135, 04035 